\title{
Anti-Microbial Activity and Spectro-Chemical Investigation of Ink Extracts of Sepiella inermis (Van Hasselt 1835)
}

\author{
Dasal VASANTHARAJA ${ }^{1}$, Vaithilingam RAVITCHANDIRANE ${ }^{1 *}$, Veerappan ANANDAN ${ }^{1}$ \\ ${ }^{1}$ Kanchi Mamunivar Centre for Post Graduate Studies, Department of Zoology, 605 008, Puducherry, India; vairavit@yahoo.co.in ("corresponding author)
}

\begin{abstract}
The crude petroleum ether and methanol ink extracts of Sepiella inermis were tested for their antimicrobial activity against human pathogenic fungi and bacteria by disc diffusion method. Spectral analysis was carried out by UV-VIS spectrophotometer, FT-IR, Raman IR and GC-MS. Of the two solvent extracts, only methanol extract was active and no activity was detected in petroleum ether extract. The human pathogenic fungus Candida albicans and bacterium Proteus vulgaris were found to be highly sensitive, with an inhibition zone of 20 and $19 \mathrm{~mm}$ respectively. GC-MS of methanol ink extract revealed sixteen compounds belonging to the derivatives of dihydroxy indole-2-carboxylic acid and dihydroxyindole. These investigations proved that methanol ink extract of Sepiella inermis possess significant antimicrobial property against both fungus and gram -ve bacteria. Since ink of sepia is available abundantly as a waste material, studies focused on isolation and characterization of bioactive substances pave the way for new antimicrobial compounds.
\end{abstract}

Keywords: anti-fungal, cuttle fish, GC-MS, gram -ve bacteria, sepia waste

\section{Introduction}

The Ocean is the mother of life and it harbours a vast variety of marine organisms that are diverse in their physiology and adaptation. Since they thrive in a different kind of environment, these organisms develop certain adaptive mechanisms which may be useful for their defense. The result of these adaptations is that almost every classes of marine organisms produce a variety of molecules with unique structural features (Carte, 1996). The cuttlefish, Sepiella inermis, commonly called spineless cuttlefish, is one of the major export oriented marine food resources exploited in Tamil Nadu and Puducherry coastal waters. Sepiella inermis produces a dark ink, constituted of a suspension of melanin granules in a viscous colourless medium, for its defense (James and Amy, 2010). The ink of sepia is available abundantly as an industrial waste material, while processing sepia for its export as food, it is not considered an edible portion. But the ink of cuttlefish was recognized as a potential source of bioactive compounds and it is a traditional Chinese medicine, listed in the Compendium of Material Medica; it possesses many interesting properties like antiseptic, antioxidant, antitumor and antibacterial activities, against different types of microorganisms (Lei et al., 2007). Based on the above facts, the present study was carried out to characterize the bioactive compounds present in the crude petroleum ether and methanol ink extracts of Sepiella inermis through UV, FT-IR and GC-MS and to test the antibacterial and antifungal properties of the ink.

\section{Materials and methods}

Fish collection and preparation of ink extract

Fresh Sepiella inermis was collected from fishing vessels of Puducherry coastal waters $\left(11^{\circ} 46^{\prime}\right.$ and $12^{\circ} 03^{\prime} \mathrm{N} ; 79^{\circ} 36^{\prime}$ and $\left.79^{\circ} 53^{\prime} \mathrm{E}\right)$. After identification, the ink-sacs were carefully removed from fresh individuals and the ink was collected and air dried at room temperature. $100 \mathrm{~g}$ of air dried ink was subjected to pulverization, using mortar and pestle. Pulverized ink powder was soaked in $200 \mathrm{ml}$ of petroleum ether $\left(40-60^{\circ} \mathrm{C}\right)$ and the same, separately, for methanol, shaken in a flask shaker (Remi) at room temperature for 8-10 h, after which it was concentrated in vacuum (Ravichandiran et al., 2013). The crude extract obtained in each case was weighed ( $1 \mathrm{~g}$ for petroleum ether and $1.2 \mathrm{~g}$ for methanol) and used for further analyses.

Screening for Antimicrobial activity

The well characterized fungal strain Candida albicans and bacterial strains Bacillus subtilis, Staphylococcus aureus, Escherichia coli, Psuedomonas aeruginosa and Proteus vulgaris were obtained from the Department of Plant Science, Tagore 
274

Arts College, Puducherry. The fungal culture was multiplied and maintained in Potato Dextrose Agar (PDA) medium at $\mathrm{pH} 6.5$ and the bacterial cultures were maintained on Nutrient Agar Medium at pH 7. The anti-microbial activity was determined by Disc diffusion technique (McCaffrey and Erdean, 1985). 20ul of each of the two ink extracts were impregnated to $6 \mathrm{~mm}$ dia. Whatman No. 1 paper discs. Further, they were aseptically placed at equidistance on PDA seeded with the test microorganisms. All the inoculated plates, along with respective solvent control, were incubated at $26 \pm 2{ }^{\circ} \mathrm{C}$ for $30-48$ hours. After $30-48$ hours the plates were observed for the development of zone of inhibition and the values were recorded. Each test was done in duplicate.

Spectral analysis

The column purified methanol ink extract of Sepiella irmis were scanned in UV-VIZ spectrophotometer (SHIMADZU-1800, Japan) between $200 \mathrm{~nm}$ and $400 \mathrm{~nm}$. IR and Raman spectra were recorded between 4000 to 500 $\mathrm{cm}^{-1}$ in FT-IR spectrophotometer (Thermo Nicolet- 6700 (2334), USA). The extract was subjected to GC-MS (SHIMADZU QP 2010, Japan). Mass spectra (EIMS) were recorded for each compound separated in succession by gas chromatography, and relative intensities corresponding to their $R_{t}$ of the molecular ion peak, and the fragment ion peaks, were normalized with respect to the base peak.

\section{Results and discussion}

The results of the antimicrobial activity of petroleum ether and methanol ink extracts of Sepiella inermis are shown in Fig. 1. Of the two solvent extracts, only methanol extract was active and no activity was detected in petroleum ether extract. The unicellular human pathogenic fungus Candida albicans was found to be highly sensitive, with an inhibition zone of $20 \mathrm{~mm}$. Proteus vulgaris was highly sensitive with an inhibition zone of $19 \mathrm{~mm}$. The other bacteria were moderately sensitive, with an inhibition zone ranging between $11 \mathrm{~mm}$ to $14 \mathrm{~mm}$.

The spectral analyses have been carried out only to methanol extract, since of the two solvent extracts, only methanol extract was active and exhibited zone of inhibition against bacterial and fungal strains. The UV spectral analysis of methanol extract showed absorption maxima at 274 and $286 \lambda$, suggesting the benzenoid nature

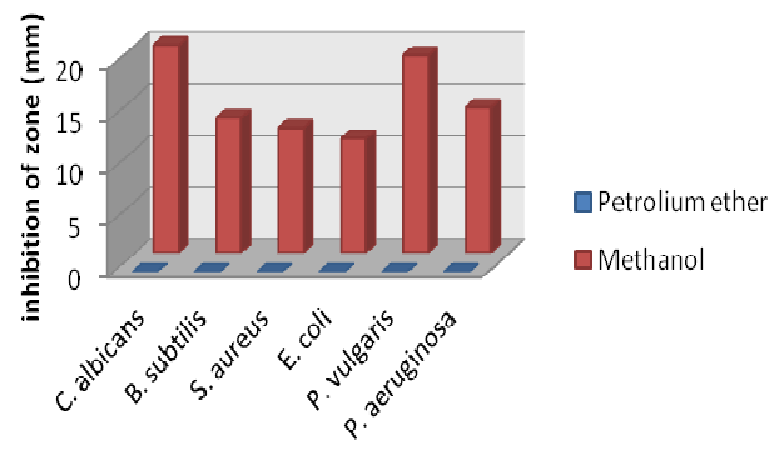

Fig. 1. Antimicrobial activity of ink extracts of Sepiella inermis of the compounds. The IR and Raman spectra provided valuable information regarding the functional groups of the crude methanol ink extract of Sepiella inermis (Fig. 2 and Fig. 3). The vibrational frequencies occurring at $3513.7 \mathrm{~cm}^{-1}$ (broad) and $3458 \mathrm{~cm}^{-1}$ inferred the N-H stretching. The bands at 1607.1 and $572.2 \mathrm{~cm}^{-1}$ corresponded to $\mathrm{C}=\mathrm{C}$ stretching and $\mathrm{C}=\mathrm{O}$ out plane stretching respectively. The signals at $1234.4 \mathrm{~cm}^{-1}$ attributed to $\mathrm{N}-\mathrm{H}$ in plane vibration. The signals appearing at $1123.4 \mathrm{~cm}^{-1}$ and $792 \mathrm{~cm}^{-1}$ corresponded to $\mathrm{C}-\mathrm{H}$ in plane bending and out of plane bending vibrations respectively. The band at $1056.8 \mathrm{~cm}^{-1}$ indicates to $\mathrm{C}-\mathrm{O}$ stretching and $630.9 \mathrm{~cm}^{-1}$ was assigned to $\mathrm{C}-\mathrm{C}-\mathrm{C}$ bending vibrations.

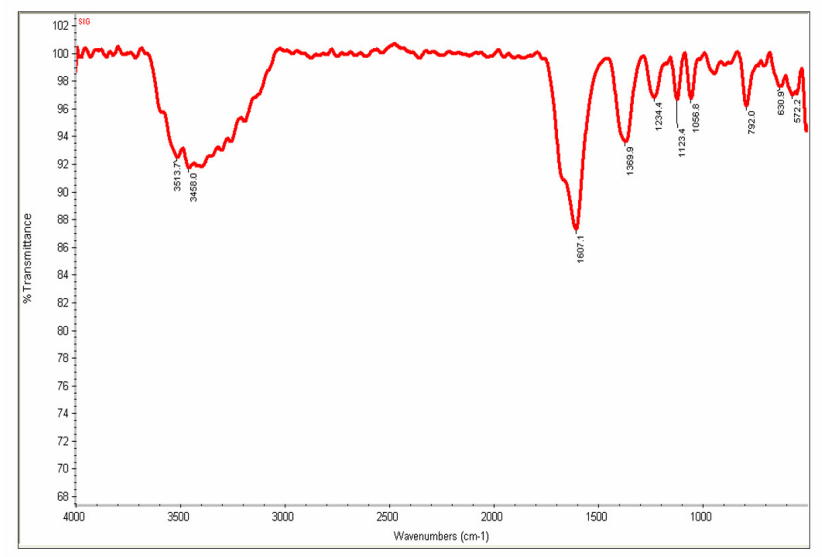

Fig.2. FT-IR spectrum of crude methanol ink extract of Sepiella inermis

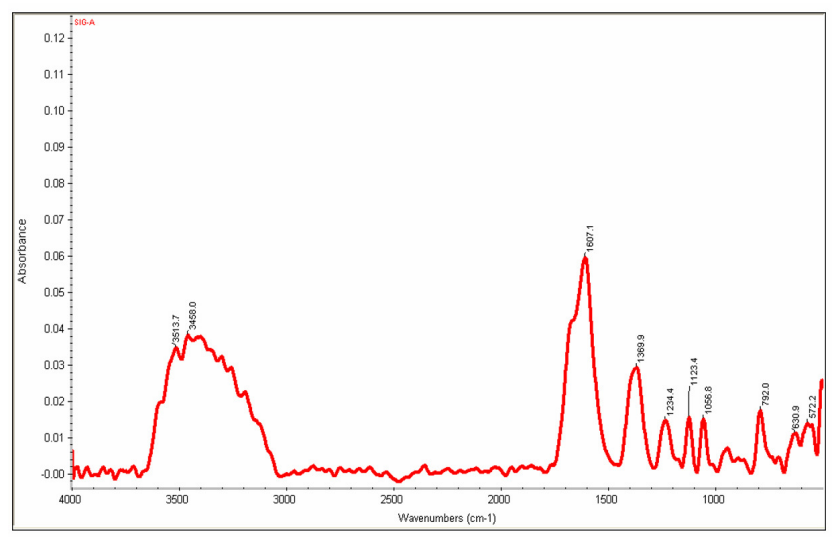

Fig. 3. Raman IR spectrum of crude methanol ink extract of Sepiella inermis

The GC-MS of methanol extract exhibited sixteen peaks, with the retention times ranging from 6.388 to $24.250 \mathrm{~min}$ (Fig. 4). The fragmentation pattern that resulted from the positive electron impact mass spectrum of all the sixteen compounds were characterized as diethylene glycol, 1H-indole, benzamide, benzaldehyde, methyl paraben, 1, 2- benenedicarboxylic acid, 1, 6 - dimethyl- 4(1-methyethyl), indole- 3- carboxaldehyde, di-isobutyl phthalate, 1-H-Indole-3-carboxaldehyde, methyl palmitate, 3, 5- ditert-butyl-4-trimethyl siloxytoluene, dibutyl phthalate, dihydroxy phthalate, dicyclohexyl phthalate, isooctyl phthalate. 


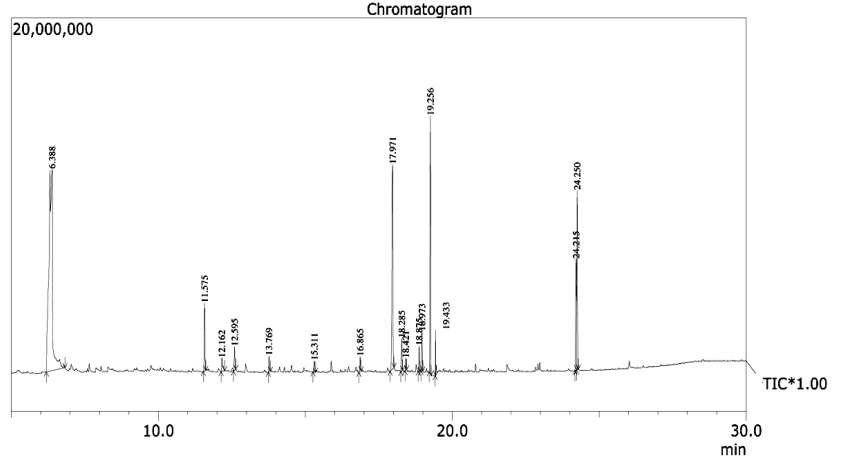

Fig. 4. GC-MS of crude methanol ink extract of Sepiella inermis

In the present study, the crude methanol ink extract of Sepiella inermis exhibited a significant antifungal activity against Candida albicans to the tune of $20 \mathrm{~mm}$ IZD. Among the bacteria tested, Proteus vulgaris showed maximum inhibition zone of $19 \mathrm{~mm}$ IZD, whereas all other bacteria exhibit a zone of inhibition ranging from 12-14 mm IZD. The most valuable finding was that the crude methanol extract showed strong inhibition against gram-negative strain of Proteus vulgaris. Generally, gram-negative bacteria are less sensitive to antibiotics, due to the presence of multi-layered cell wall consisting of peptidoglycan, which is surrounded by an extra layer of lipid membrane, containing lipopolysaccharides and lipoproteins (Pegler and Healy, 2007). This extra layer of lipid membrane interfere the action of drug penetration to peptidoglycan cell wall. But a gram positive bacterium is highly sensitive to antibiotics, because they devoid of extra layer of lipid membrane. Therefore, when the structural integrity of this cell wall is compromised, the cell loses its protection and ultimately dies (Hugen Holtz, 2002). The GC-MS investigation of methanol ink extract of Sepiella inermis revealed the presence of a mixture of oligomeric structures incorporating dihydroxy indole-2carboxylic acid derived units and dihydroxyindole-derived bioactive compounds. Neifar $e t$ al. (2009) have reported that dihyroxyindole and dicarboxylic acid from Sepia officinalis exhibited significant medicinal properties like microbial inhibition and platelet agglutination (Ramasamy et al., 2011). Sinha et al. (1997) suggested that carboxylic acid substitution in naturally occurring amine and peptides was capable of inhibiting the growth of gram negative bacteria and the possible mechanism of anti-microbial action of these metabolites usually differ (Kisliuk, 1989). Most of the antimicrobial compounds kill microbes by a common mechanism, which involves direct electrostatic interactions with negatively charged phospholipids on physical disruption and solubilisation (Boman, 1995; Andreu and Rivas, 1999) or by forming large pores in the bacterial cell membrane (Ebran et al., 1999). Therefore, it is clear that the present study revealed that the crude methanol ink extract of Sepiella inermis was capable of causing impairment of extra layer of lipid membrane, due to the presence of pharmacophoric functional groups like carboxylic acid, diethyl phthalate and methyl indole-3-carboxylate. On the other hand, petroleum ether extract showed no antimicrobial activity, due to the absence of antimicrobial compounds.

\section{Conclusions}

The study has proved that the methanol ink extract of Sepiella inermis was capable of inhibiting the growth of both gram positive and gram negative pathogenic bacteria and fungus, indicating its wide spectrum of antimicrobial property. Since the ink of sepia is available abundantly as a waste material, if more attention is given on the isolation and characterization of its bioactive compounds, it may pave the way for the development of new drugs from sepia waste.

\section{References}

Andreu D, Rivas L (1999). Animal antimicrobial peptides; an overview. Biopolymers 47:415-433.

Boman HB (1995). Peptide antibiotics and their role in innate immunity. Annu Rev Immunol 13:61-92.

Carte BK (1996). Biomedical potential of marine products. Biosciences 271-286.

Ebran NS, Julien N, Orange P, Saglio C, Lemaitre, Molle G (1999). Pore-forming properties and antibacterial activity of proteins extracted from epidermal mucus of fish. Comp Biochem Phsiol 2:181-189.

Hugen Holtz P (2002). Exploring prokaryotic diversity in the genomic era. Genome Biol 3(2):1461-1471.

James BW, Amy EM (2010). Caribbean reef squid use ink as a defense against predatory French grunts. J Exp Mar Biol Ecol 388:20-27.

Kisliuk RL (1989). Amino acids, peptides and proteins, In Principles of medicinal chemistry. Varghese publishing house, Bombay 551-570.

Lei M, Wang JF, Wang YM, Pang L, Wang Y, Xu W (2007). Study of the radio-productive effect of cuttle fish ink on hemopoietic injury. Asia Pac J Clin Nutr 16:239-243.

McCaffrey EJ, Erdean R (1985). Antimicrobial activity of tropical and subtropical sponges. Mar Biol 89:1-8.

Neifar A, Ben Rebah F, Gargouri A, Abdel Mouleh A (2009). Physicochemical characterization of Sepia officinalis ink and the effects of the storage conditions of the coagulation process. J Mar Biol Assoc UK 89(4):803-807.

Pegler S, Healy B (2007). In patients allergic to penicillin consider second and third generation cepholosporins for life threatening infections. BMJ 335 (7627):991.

Ramasamy P, Barwin Vino A, Saravanan R, Subhapradha N, Vairamani S, Shanmugam A (2011). Screening of antimicrobial potential of polysaccharide from cuttlebone and methanolic extract from body tissue of Sepia prashadi Winkworth, 1936. Asian Pac J Trop Biomed 1 (Suppl 2) S244-248.

Ravichandiran M, Thiripurasalini S, Ravitchandirane V, Gopalane S, Stella C (2013). Chemical constituents and anti-tuberculosis activity of ink extracts of cuttlefish, Sepiella inermis J Coas Life Med 1(4):253-257.

Sinha AK, Mehra SM, Pathak RC, Sinha GK (1997). Antibacterial activity of volatile oils from some indigenous plants. Indian J Exp Biol 15:339- 340. 